\title{
ANALYSIS OF INFLUENTIAL FACTORS AND ASSOCIATION RULES FOR BRIDGE DECK DETERIORATION WITH UTILIZATION OF NATIONAL BRIDGE INVENTORY
}

Rong Yau Huang

Graduate Institute of Construction Engineering and Management, National Central University, Taoyuan, Taiwan, R.O.C.

Ping Fu Chen

Department of Civil Engineering, National Central University, Taoyuan, Taiwan, R.O.C., pingfuchen@hotmail.com

Follow this and additional works at: https://jmstt.ntou.edu.tw/journal

Part of the Civil and Environmental Engineering Commons

\section{Recommended Citation}

Huang, Rong Yau and Chen, Ping Fu (2012) "ANALYSIS OF INFLUENTIAL FACTORS AND ASSOCIATION RULES FOR BRIDGE DECK DETERIORATION WITH UTILIZATION OF NATIONAL BRIDGE INVENTORY," Journal of Marine Science and Technology: Vol. 20: Iss. 3, Article 13.

DOI: $10.51400 / 2709-6998.1812$

Available at: https://jmstt.ntou.edu.tw/journal/vol20/iss3/13

This Research Article is brought to you for free and open access by Journal of Marine Science and Technology. It has been accepted for inclusion in Journal of Marine Science and Technology by an authorized editor of Journal of Marine Science and Technology. 
ANALYSIS OF INFLUENTIAL FACTORS AND ASSOCIATION RULES FOR BRIDGE DECK DETERIORATION WITH UTILIZATION OF NATIONAL BRIDGE INVENTORY

Acknowledgements

This research was supported by National Science Council (NSC 100-2218-E-008-007-). 


\title{
ANALYSIS OF INFLUENTIAL FACTORS AND ASSOCIATION RULES FOR BRIDGE DECK DETERIORATION WITH UTILIZATION OF NATIONAL BRIDGE INVENTORY
}

\author{
Rong Yau Huang ${ }^{1}$ and Ping Fu Chen ${ }^{2}$
}

Key words: data mining, bridge maintenance, national bridge inventory, two-steps, C5.0.

\begin{abstract}
Bridge is the hub of the roads and plays a crucial role in transportation. In recent years, the age of most bridges in Taiwan has gotten old gradually; as a result, the bridges deteriorate and need to be fixed and maintained. Nevertheless, it is not easy to predict the timing of bridge deterioration, and such situation has become one of the important issues in introducing the concept of preventive maintenance. In fact, in order to control the condition of bridge deterioration, many countries have set up bridge management system and regulated methods and mechanism of inspection. The record of bridge maintenance and inspection history is therefore well preserved, but the number of researches utilizing value added analysis of bridge deterioration with database of history is limited. There are many factors that affect bridge deterioration. In addition to the materials and types of elements of the bridges, it is associated with external environments as well, including environmental factors as traffic flow or rainfall. The present paper adopts National Bridge Inventory (NBI) established by USA since 1992 to process data mining. Currently, the database is the most abundant and publicly accessible database of bridge history, not only collecting basic information of bridges in each state, but keeping a complete record of the inspection history every year. This research processes analysis by means of K-Means, Two -Steps, and C5.0, categorizing bridges into several different clusters and depicting the decision-making tree of clustering and rules of bridge deterioration. In the future, bridge maintenance personnel can gain a clear idea of the cluster of the bridges they are responsible for according to
\end{abstract}

Paper submitted 03/25/11; revised 04/23/12; accepted 05/03/12. Author for correspondence: Ping-Fu Chen (e-mail: pingfuchen@hotmail.com).

${ }^{I}$ Graduate Institute of Construction Engineering and Management, National Central University, Taoyuan, Taiwan, R.O.C.

${ }^{2}$ Department of Civil Engineering, National Central University, Taoyuan, Taiwan, R.O.C. the results of the decision tree. They can also cope with possible deterioration in advance by introducing the concept of preventive maintenance management. Consequently, the disasters can be avoided, the safety of pedestrians can be ensured, and the bridge maintenance budget of public engineering can be economized.

\section{INTRODUCTION}

Due to the fact that there are many mountains and rivers in Taiwan, it takes a bridge to connect two places. Nevertheless, complex and diversified topography has led to many tough tests. Different tendencies of bridge deterioration have resulted from the interactive effects of different materials, patterns and environments, which has become a difficult issue for bridge maintenance sections to tackle with. Therefore, the concept of preventive maintenance must be introduced to prevent sudden bridge deterioration that endangers the safety of the pedestrian's life and property. One of the requirements of preventive maintenance is to control the bridge's elements precisely. Only when the tendencies of bridge deterioration are controlled can we take necessary actions to ensure good bridge condition and lengthen life of bridge.

However, deterioration of bridge elements is influenced by multiple effects of many factors. In addition to factors like materials, construction forms, and geometry, it is tested by external environments, including rainfall and traffic flow. In spite of the past studies aiming at discussions on factors of bridge deterioration, the topics were mostly limited to subjective judgment, and only a few analyzed deterioration in accordance with historical database. Currently, many countries have set up bridge management system for managing basic information and maintenance records of bridges, and endeavor themselves to expand the follow-up functions of bridge management system with the purpose of bringing the value of records to a full play. Accordingly, since 1990, Taiwan has established bridge management system and introduced DER\&U inspection method to categorize the bridge into 21 elements. Evaluation is then undertaken by degree, extent, relevancy, and urgency. The evaluated results are divided into 
Table 1. Studies of related bridge data mining.

\begin{tabular}{|c|c|c|}
\hline Authors & Topic & Content \\
\hline Jaeho Lee et al. [8] & $\begin{array}{l}\text { Improved reliability of bridge management } \\
\text { system's information }\end{array}$ & $\begin{array}{l}\text { The problem of missing column in existing bridge management } \\
\text { system is resolved by ANN-BPM. NBI is used for case study. } \\
\text { The study enhances the reliability of existing data to make } \\
\text { future analysis more accurate. }\end{array}$ \\
\hline Brent M. Phares et al. [13] & Reliability of visual bridge inspection & $\begin{array}{l}\text { Practical cases, } t \text {-test, and historical data such as bridge deck, } \\
\text { superstructure and substructure, are explored in order to un- } \\
\text { derstand accuracy and reliability of data in the confidence in- } \\
\text { terval. }\end{array}$ \\
\hline Melik Bolukbasi et al. [3] & Estimate of bridge state & $\begin{array}{l}\text { Condition index of deck, superstructure and substructure in } \\
\text { NBI is estimated by simple multiple regression. The study } \\
\text { takes into account three key factors leading to deterioration, } \\
\text { including material (steel, concrete, prestressed concrete), } \\
\text { highway grade (inter-state, non inter-state, and traffic (ADT is } \\
\text { above } 5000,5000 \sim 10,000,10,000 \text { ) }\end{array}$ \\
\hline Ying-Ming Wang et al. [16] & Estimate of bridge state & Bridge state and weighting are deducted by evidence reasoning. \\
\hline
\end{tabular}

four levels- 1 is the best condition and 4 is the worst. Besides, the inspective value 0 refers to absence of the element or inability to inspect. Because some data attributes involve with national defense secrets, Taiwan bridge management system opens up for the public with some limits, which leads to difficulty in proceeding analysis of bridge deterioration; as a result, data from bridge management system in other region must be analyzed and verified. In 1992, United States built up National Bridge Inventory compiled by the Federal Highway Administration. The main purpose was to register information of bridges over 20 feet $(600,000$ bridges $)$ in U.S.A., including attributes like ID number, materials, type, operation condition, age, and etc. It has generated considerable space of sample analysis in respect to data analysis. Although some attributes is absent or is incomplete, it is worthy analyzing as a whole.

The study probes into issues with utilization of NBI in U.S.A. It selected Florida state which climate is similar to that in Taiwan to undertake analysis beginning from understanding NBI attributes and filtering inappropriate and incorrect samples. Based on bridges' data itself, bridges are divided into 5 clusters by Two Steps. By C5.0 Decision Tree, this research tries to set up the classification rules of each cluster. Besides, this study uses linear regression analysis of inspection data of these five clusters, and gain deterioration rate of each cluster. Afterwards, every bridge in the state can apply to the rule to confirm the cluster it subordinates. In other words, the deterioration rate of the cluster is the reference value of that bridge. In short, we hope the analytical model of NBI can function as reference to calculating the deterioration rate of bridges in Taiwan.

\section{THE TRANSCEIVER STRUCTURE}

\section{Prediction of Bridge Condition with Data Mining}

This study undertakes data mining on bridges' basic in- formation and the past maintenance record in NBI database. Several scholars in the world have gone through case studies with different methods for data mining in NBI database and have concluded possible factors to estimate the trend of deterioration. Although different factors are used in each study, the results are satisfying. Table 1 presents the summary of the related studies.

\section{Clustering}

The method in cluster analysis is unsupervised, so there are no subjective categories when clustering is administered. Therefore, this paper divides data into clusters by certain standards before reasonably establish categorization. Since cluster analysis gather objects with similar data together to analyze and illustrate them, it is often used to classify data for succeeding data mining or modeling. For example, market is segregated before people adopt different marketing strategies. Common cluster analyses include K-means, Two Steps, and etc., as what bellows show:

In 1967, K-means published formally [9]. The operation process is carried out by the following steps.

(1) Select K Initial Cluster Centers by random.

(2) Classify data into the cluster closest to the center.

(3) Calculate new cluster centers.

(4) When the distance between clusters is the same, terminate calculation.

K-means is part of cluster analysis techniques with extensive application. Data is processed depending on initial cluster center, and it is possible to ignore the results of cluster analysis with local minimum. Thus, number of clusters needs further study [6].

Two steps can simultaneously process continuous and categorical variables or attributes. That is to say, when clustering is undertaken, data with various sizes can be processed as long 
as it is subject to two principles. First, there is no multicollinearity among variables. Secondly, variables must be distributed normally [12]. Generally, the basic concept is to implement clustering by two stages. This algorithm can be divided into two steps, pre-cluster and cluster. What follows is the description of them.

\section{1) Pre-Cluster Step}

Balance iterative reducing and clustering using hierarchies (BIRCH) by large samples in hierarchical cluster is adopted here. After input all data, compress the original data as subclusters easy to process.

\section{2) Cluster}

In this step, log serves as the formula of distance measurement. In step 1, cluster analysis is conducted again for each cluster, and sub-clusters are gradually integrated into larger ones. Due to no need of inputting data again, it is suitable for large sample processing. The characteristics are automatically discerning the number of the clusters simultaneously or setting up the cluster number manually.

\section{Classification}

Decision tree analysis represents each classification hierarchically and demonstrates the knowledge structurally. Each branch belongs to an attribute of the classification, and the leaves are part of the data cluster. As a result, with the framework of decision tree, the samples can be categorized by different characteristics of the attributes. So, the future studies just need to derive the bridge to its cluster by the structure of decision tree. The popular classification methods currently include C5.0 and C\&R Tree (Classification and Regression Tree, CART), which are briefly introduced as what follows.

\section{1) $C 5.0$}

C5.0 decision tree is gradually developed from ID3 (Interactive Dichotomizer). It is a kind of decision tree algorithm using inductive, and is based on an information theory proposed by J. Ross Quinlan to form the method of decision tree with a set of training samples. By means of measuring the entropy of each attribute and comparing the attributes to find the smallest entropy, decision tree can be constructed to differentiate the attributes of the most effective training sample classification. Soon afterwards, ID3 is upgraded by Quinlan as C4.5 in 1993, with the property to process continuous data and moderately cut the branches of decision tree [11]. After upgraded to C4.5, it is C5.0 launched by Quinlan adopting boosting's algorithm to raise the accurate rate of model. In addition, the calculation rate of $\mathrm{C} 4.5$ rises because it occupies less system resource and memory. It generates decision tree and rule set as well [6]. The advantages of adopting C5.0 include: (1) it is not easy for C5.0 to make mistakes in coping with problems and entering attributes. (2) It does not take long training times for C5.0 to proceed estimation. (3) The

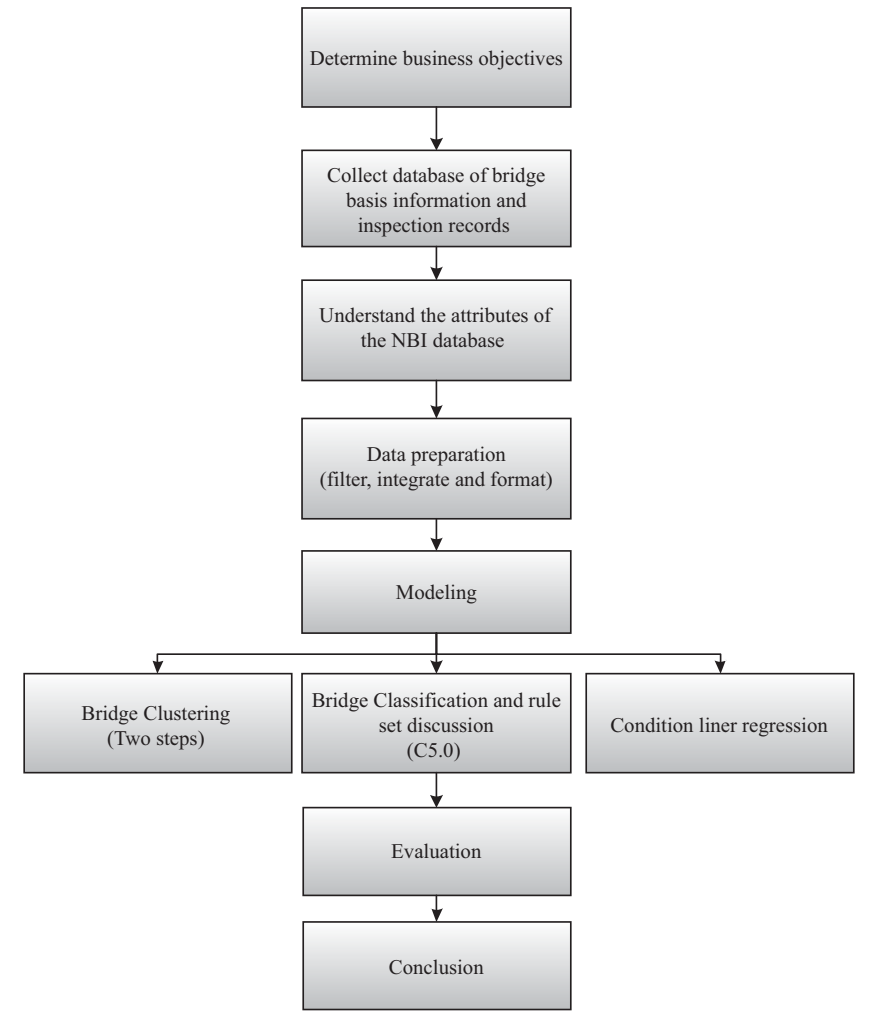

Fig. 1. Research flow.

decision tree produced by $\mathrm{C} 5.0$ is better comprehended than other relative ones. (4) C5.0 uses accurate classification techniques.

\section{2) $C \& R$ Tree}

C\&R Tree (Classification and Regression Tree, CART) represents the results of classification by the structure of a tree. Proposed by Breiman, the nodes of C\&R Tree are exactly its testing conditions, while the branches are its testing results [4]. Given that the target variables are numeric ones, it is called Regression Tree; if the target variables are class ones, it is called Classification Tree. One characteristic of this decision tree is that both class data and numeric data can be treated and it takes short time to generate a decision tree. C\&R Tree consists of two procedures-(1) Build structure of tree. (2) Cut structure of tree.

To avoid being over-subjective, this study conducts Two Steps with the clustering method. Also, it administers C5.0 with the classification method in considerations of the largescale database to proceed calculation by business software of data mining SPSS Clementine.

\section{METHODOLOGY}

To ensure the accurateness and operability of the model proposed by this study, it consults the existing standard procedures of data mining and select to use CRISP-DM. The research flow is listed below as Fig. 1. 


\section{Determine Business Objects}

The purpose of this research is to build up a definitely operable rule sets of bridge elements' deterioration for maintenance personnel to control the deterioration tendencies by the rules, and take responsive maintenance strategies in advance. In this study, we will take one of the main elements of the bridge, deck, as the case subject.

\section{Collect Database of Bridge Basis Information and Inspection Records}

This study collected NBI compiled by FHWA and selected Florida state where the environment was similar to that in Taiwan for case analysis. The collected data included basic and historical inspection data, and the range was from 1992 to 2010.

\section{Stages of Data Comprehension (Understanding the Attributes of the NBI Database)}

This stage focuses on identifying the meaning of the attributes in database. There are 116 attributes in NBI database. Each attribute is described in detail in Recording and Coding Guide for the Structure Inventory and Appraisal of the Nation's Bridges with examples for definition and explanation. Besides, each has its own coding way, though the corresponding value to the coding way does not always signify. However, a definite coding system helps prepare for operations like deletion, integration or disperse for succeeding data.

This is the most important step in data mining, because the huge and complicated data without systematical organization tend to cause noises after molding, which has great impact on the correctness of the training or testing results. Therefore, this stage emphasizes on carefully processing data attributes, which can be roughly categorized into attributes integration, outlier, discrete, and etc. Take NBI as example, there were 116 NBI attributes divided into basic information, structural material information, transportation information, geometry information, navigation information, road level information, load information, evaluation, suggestive improvement actions, inspection information, and so on. After consulted the professionals' opinions, and examined the necessity of the existing attributes one by one, the attributes were converged to several valid ones. They were used in clustering except inspection information, which serve as the foundation to determine the deterioration rate. The content of each attribute is listed as follows.

NBI roughly divided the whole bridge into deck, superstructure and substructure, and asked inspection personnel to evaluate them by $0-9$ points with visual inspection. " $\mathrm{N}$ " is given when the bridge does not have the element. In the past researches, it was regarded as serious condition when the evaluated score $\leqq 3$ and the corresponding measures must be taken immediately. The inspection standards are shown in the following table.

Since data was entered manually, there might be problems like data missing or errors. In addition, people who filled in
Table 2. NBI attributes categories.

\begin{tabular}{|l|}
\hline \multicolumn{1}{|c|}{ NBI attributes } \\
\hline Identification \\
\hline Structure Type and Material \\
\hline Age and Service \\
\hline Geometric Data \\
\hline Navigation \\
\hline Classification \\
\hline Condition \\
\hline Load Rating and Posting \\
\hline Appraisal \\
\hline Proposed Improvements \\
\hline Inspections \\
\hline
\end{tabular}

Table 3. Bridge component condition rating.

\begin{tabular}{|c|l|}
\hline Code & \multicolumn{1}{|c|}{ Description } \\
\hline $\mathrm{N}$ & Not applicable \\
\hline 9 & Excellent condition \\
\hline 8 & Very good condition-no problems noted \\
\hline 7 & Good condition-some minor problems \\
\hline 6 & Satisfactory condition \\
\hline 5 & Fair condition \\
\hline 4 & Poor condition \\
\hline 3 & Serious condition \\
\hline 2 & Critical condition \\
\hline 1 & Imminent failure condition \\
\hline 0 & Failed condition \\
\hline
\end{tabular}

the data might not be in the same section, so subjective judgment might appear. Such records would have effects on the outcomes of the following data mining; thus this research deleted the likely wrong data by four principles, as we may see in the following.

(1) Elements with $\mathrm{N}$ classification signify that the bridge is not applicable, and does not have to be included in analysis.

(2) The reason why the condition values of the bridge between the previous and succeeding years differing considerably may be that subjective judgment or sudden serious deterioration caused by accidents. This study mainly probes into natural deterioration of bridges, and eliminates deterioration caused by accidents.

(3) Abnormal conditions of the elements, like the abnormal record from the mentioned accidents, or beyond the recording range $0-9$.

(4) Missing basic information, like age, patterns of construction, or materials.

(5) Some errors from manual entering data or wrong bridge information have to be corrected. For example, Minimum Vertical Underclearance and Waterway Adequacy cannot 


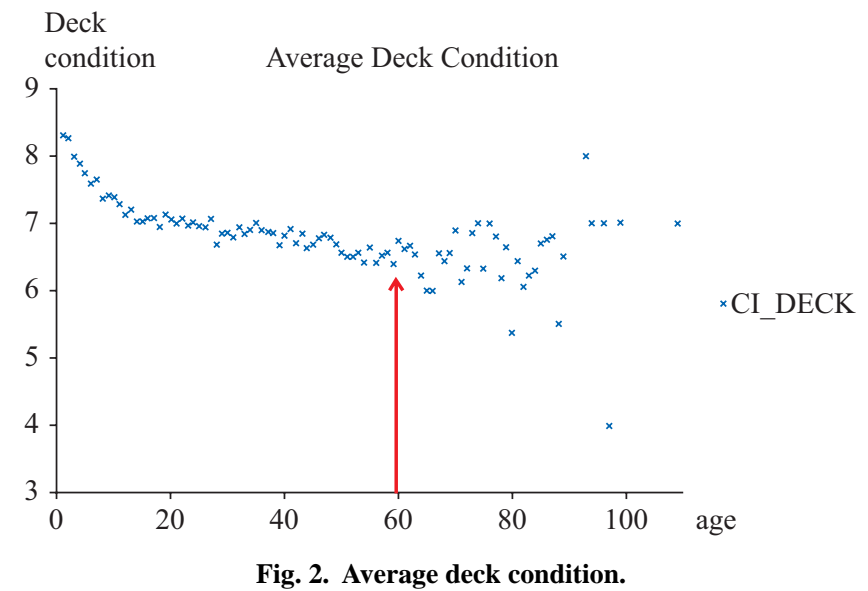

be $\mathrm{N}$ at the same time. If Minimum Vertical Underclearance is 0 , the waterway adequacy attribute should be input. Therefore, when these two attributes are marked as N, the data should be abandoned.

(6) Due to some bridges' ages, there were no historical records of maintenance, leading to difficulty in judging their current maintenance situation. Also, it tends to miscalculate the follow-up deterioration rate. Consequently, this study observed the relationship between the age of the bridge and the condition of the deck. It found that when the age of the bridge is 60 years, the condition value of the deck is 6. Quality and efficiency of the follow-up maintenance thus raises, as shown in Fig. 2. In this regard, the present research assumes that when the deck's age is approximately 60 years, the condition value should be 6 . Value above 6 is excluded.

\section{Modeling}

This stage chiefly involves with data clustering, rule extraction, and linear regression. In data clustering, it categorizes data with different methods, and discusses the influences of different cluster number on following knowledge extraction. Due to cluster number was determined by user subjectively, this study selected Two-Steps to undertake clustering operation to diminish subjective judgment. Two-Steps can process continuous attributes and categorize attributes at the same time. Namely, it can deal with data with various dimensions in clustering. After clustering, attributes were decided with C5.0. Lastly, inspection records in the same cluster were conducted with linear regression so as to understand the deterioration rate of each cluster as reference to bridge maintenance.

\section{Evaluation and Conclusion}

In evaluation stage, the previous data was administered knowledge extraction. In the above-mentioned rules of bridge deterioration, the study tried to understand the meaning of each attribute, analyze latent information, and see whether the deterioration rates tend to be the same in linear regression analysis. In the future, the mined data can serve as reference
Table 4. Clustering of bridges.

\begin{tabular}{|c|r|c|}
\hline Cluster & Number & $\begin{array}{c}\text { Deterioration rate } \\
\text { (Deck Condition/per year) }\end{array}$ \\
\hline 1 & 1,974 & 0.031 \\
\hline 2 & 1,245 & 0.036 \\
\hline 3 & 898 & 0.037 \\
\hline 4 & 613 & 0.043 \\
\hline 5 & 621 & 0.047 \\
\hline Total & 5,346 & \\
\hline
\end{tabular}

for bridge maintenance sections to conduct appropriate maintenance to achieve preventive maintenance by raising the bridge function and lengthening life of bridge.

\section{RESULTS AND DISCUSSION}

With the previous standard of CRISP-DM as the mining process, case analysis proceeded with NBI from FHWA, and Florida was selected owing to its similar environments with Taiwan's. There were 15,762 bridges in the state in 2010, but the attributes of some bridges were missing or wrong. Previous filtering principles were therefore taken for examination, showing that 5,346 bridges were eligible for analysis. A total of 58 attributes, were included in the analysis except administration information such as the management section, and nearby landmark. As for the setting of Two Steps, 3 is the minimum cluster number while 8 is the maximum. All bridges were divided into 5 clusters, and the number in each cluster after calculated by Two Steps was listed in Table 4. History of inspection record of the decks in each cluster was processed linear regression and showed their deterioration rate of each deck, as seen in Table 4.

The deterioration rate of decks in Cluster 1 is slower, approximately 0.031 year, and in Cluster 2 and Cluster 3, it is a little faster, about 0.036 0.037/year. In addition, the deterioration rate of the decks in Cluster 4 is around 0.043/year, while that in Cluster 5 is the fastest, 0.047 year. According to the construction condition evaluation, value 7 refers to the appearance of the secondary problem of deterioration and the need of fixing. In other words, when deck condition deteriorates from value 9 to value 7 , it takes 64.5 years for bridges in Cluster 1 and 42.6 years for those in Cluster 5 to deteriorate. Therefore, bridge maintenance sections have to pay more attention to maintaining bridges in Cluster 5 than those in Cluster 1. Figs. 3-7 show the results of linear regression of Cluster 1-5.

To clearly list the rules of each cluster, C5.0 was undertaken with bridge No. as the attribute and 58 factors as the input values. Thus, the number of rules in each cluster are 16 in Cluster 3, the most; Cluster 1, 2, and 4 follow, with 4-5 rules. There is only 1 rule in Cluster 5 . Table 5 listed below shows the rules in each cluster.

Four rules of Cluster 1 are indicated in Table 6. Rule 1 describes the inventory route minimum vertical clearance is 


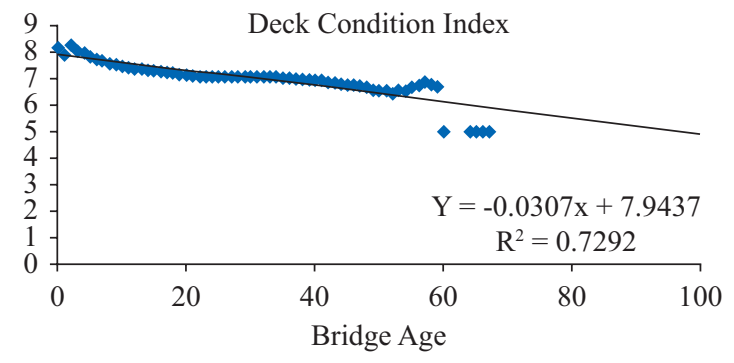

Fig. 3. Average deck condition (cluster 1).

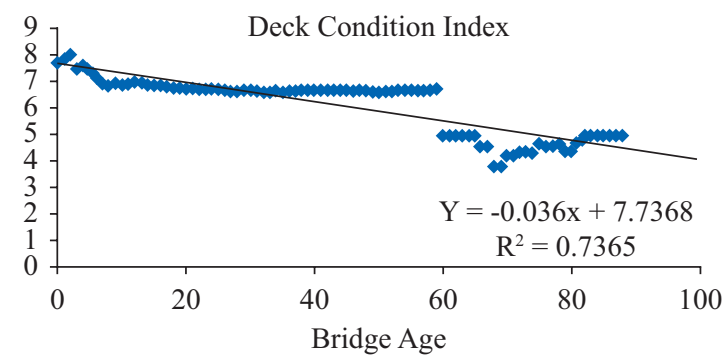

Fig. 4. Average deck condition (cluster 2).

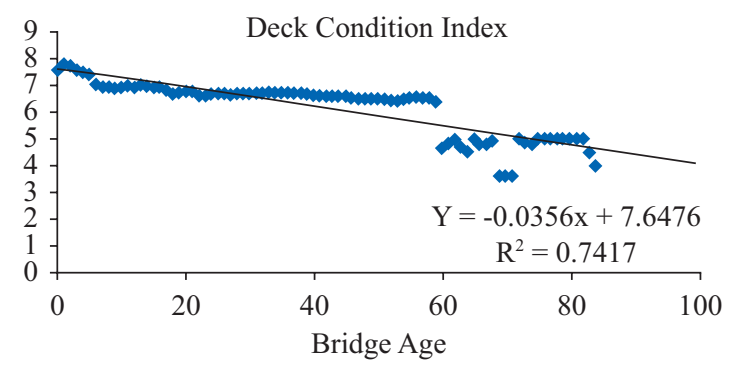

Fig. 5. Average deck condition (cluster 3).

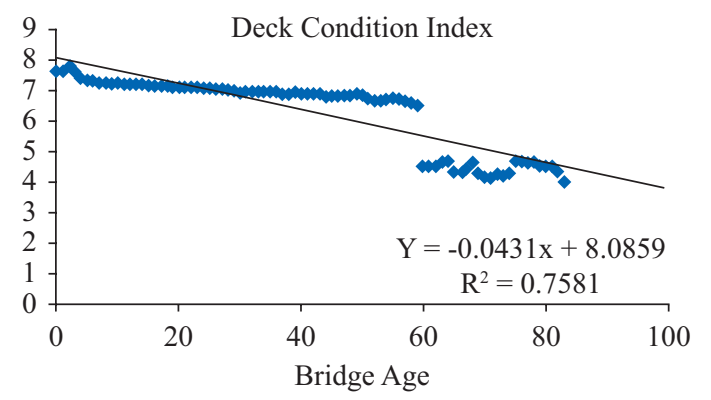

Fig. 6. Average deck condition (cluster 4).

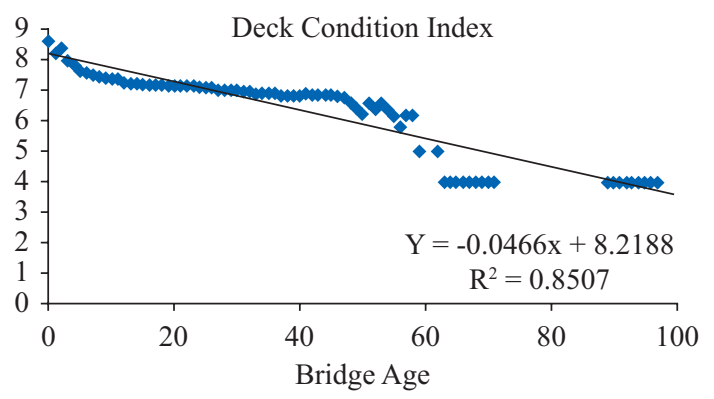

Fig. 7. Average deck condition (cluster 5).
Table 5. The number of rules.

\begin{tabular}{|c|c|}
\hline Cluster number & Rule sets \\
\hline 1 & 4 \\
\hline 2 & 4 \\
\hline 3 & 16 \\
\hline 4 & 5 \\
\hline 5 & 1 \\
\hline
\end{tabular}

Table 6. Rule sets of Cluster 1.

\begin{tabular}{|c|l|}
\hline Cluster 1 & \multicolumn{1}{c|}{ Rule Description } \\
\hline Rule 1 & $\begin{array}{l}\text { if inventory route minimum vertical clearance }>6.8 \\
\text { and minimum vertical underclearance }>2.32 \\
\text { and waterway adequacy }=\mathrm{N}\end{array}$ \\
\hline Rule 2 & $\begin{array}{l}\text { if number of approach spans }<=6 \\
\text { and min vert. underclearance }>2.32 \\
\text { and waterway adequacy }=\mathrm{N}\end{array}$ \\
\hline Rule 3 & $\begin{array}{l}\text { if type of service under bridge }=0 \\
\text { and number of approach spans }<=2 \\
\text { and designated national network }<=0\end{array}$ \\
\hline Rule 4 & $\begin{array}{l}\text { if route signing prefix }=3 \\
\text { and type of service under bridge }=3\end{array}$ \\
\hline
\end{tabular}

higher than $6.8 \mathrm{~m}$, which signifies that the bridge is interchanged with a road or other structural object on/under the bridge. In such situation, the bridge cannot be a bridge over river. The inventory route minimum vertical clearance must be above $6.8 \mathrm{~m}$, and the minimum underclearance must be more than $2.32 \mathrm{~m}$. To look up data in the database, the minimum vertical underclearance is $2.32 \mathrm{~m}$, and there are no bridges with 0 2.32 m. Since the bridge with minimum vertical underclearance 0 is a bridge over river, the logic of the two rules is correct, and can be considered as the definition of a non-bridge-over-river. Rule 2 narrates that number of approach spans is equal to or less than 6 , which explains that the length of the approach spans of the bridge must be less than 6 spans. Another item is the definition of non-bridge-over-river, same with that in Rule 1. The first item in Rule 3 indicates that the classification of usage is Other or No, and the number of span is less than 2. Besides, this bridge is not the one regulated by Nation for trucks' passing through. Therefore, it can be inferred to have lower load. In Rule 4, it regulates that route signing prefix $=3$, which tells us that the bridge is stateleveled, and type of service under bridge $=3$, meaning that it is for Pedestrian-bicycle to use. Consequently, it is inferred that most bridges in Cluster 1 are non-bridge-over-river, and are smaller ones in respect of spans. The bridge does not interchange with other structure, and is not the route of the trucks. Moreover, since most roads under the bridge are not main roads, it is less influenced by the environments. In short, this study concludes that it is associated with slower deterioration rate of the deck.

There are 4 rules in Cluster 2. Rule 1 refers to minimum lateral underclearance $>28.3 \mathrm{~m}$, indicating the longer lateral 
Table 7. Rule sets of Cluster 2.

\begin{tabular}{|c|l|}
\hline Cluster 2 & \multicolumn{1}{c|}{ Rule Description } \\
\hline Rule 1 & if minimum lateral underclearance $>28.3$ \\
\hline \multirow{5}{*}{ Rule 2 } & $\begin{array}{l}\text { if design load }>4 \\
\text { and approach roadway width }>108 \\
\text { and type of service on bridge }=1.000 \\
\text { and number of approach spans }<=2 \\
\text { and inven. Rte total horz clearance }>118 \\
\text { and min vert. underclearance }<=2.32 \\
\text { and direction of traffic }<=1 \\
\text { and deck structure type }=1.000 \\
\text { and designated national network }>0\end{array}$ \\
\hline Rule 3 & $\begin{array}{l}\text { if year built }>1,964 \\
\text { and type of service on bridge }=1.000 \\
\text { and number of approach spans }<=2 \\
\text { and min vert. underclearance }<=2.32 \\
\text { and direction of traffic }<=1 \\
\text { and designated national network }>0\end{array}$ \\
\hline \multirow{5}{*}{ Rule 4 } & $\begin{array}{l}\text { if number of approach spans }<=2 \\
\text { and length of max span }>242 \\
\text { and min vert. underclearance }<=2.32 \\
\text { and waterway adequacy }=9 \\
\text { and highway system of inventory route }>0\end{array}$ \\
\hline
\end{tabular}

distance of abutments or piers. Rule 2 has more attributes, including design load $>4$, representing the design load is $\mathrm{H} 20$ standard, or van truck with total weight of 18 tons. The width of approach $>10.8 \mathrm{~m}$, and type of service on bridge $=1$, signifying the usage on the bridge is highway. The span number of the guide passage has to be less than 2, the minimum horizontal underclearance more than $11.8 \mathrm{~m}$, and the minimum underclearance less than $2.32 \mathrm{~m}$, showing that it is a bridge over river. Also, it is a one-way road with deck structure type 1 ; that is, the bridge deck is made of concrete poured on-site. Lastly, designated national network is more than 0 , showing the bridge allows trucks' passing through. Rule 3 sets up that the bridge must be established after 1964, the usage is for highway, the span number of the guide passage is less than 2, the road of the bridge is one-way, and allows trucks' passing through. Rule 4 signifies that the span number of the guide passage is less than 2, the longest span length is more than $24.2 \mathrm{~m}$, and the minimum underclearance is less than $2.32 \mathrm{~m}$. Besides, the waterway adequacy is 9 , showing that the bridge deck and roadway is above flood water elevations (high water). Chance of overtopping is remote, so the waterway seldom emerges above the bridge. Furthermore, Inventory Route is on the NHS. In other words, though the bridge is one over river, the volume of the river is sufficient with scare chances for water split on the deck, and the span is long. Therefore, it is inferred that it has certain load of traffic.

On a whole, most bridges in Cluster 2 are those with certain load of traffic. Also, part of them are bridges over river. However, the waterway adequacy is good with less impact of split water. Consequently, the effects on deterioration rate mostly
Table 8. Rule sets of Cluster 3.

\begin{tabular}{|c|c|}
\hline Cluster 3 & Rule Description \\
\hline Rule 1 & $\begin{array}{l}\text { if route signing prefix }=2 \\
\text { and type of service under bridge }=5 \\
\text { and number of approach spans }<=2 \\
\text { and highway system of inventory route }<=0\end{array}$ \\
\hline Rule 2 & $\begin{array}{l}\text { if number of approach spans }<=2 \\
\text { and length of max span }<=24.2 \\
\text { and min vert. underclearance }<=2.32 \\
\text { and highway system of inventory route }>0 \\
\text { and designated national network }<=0\end{array}$ \\
\hline Rule 3 & $\begin{array}{l}\text { if year built }<=1,964 \\
\text { and min vert. underclearance }<=2.32 \\
\text { and deck structure type }=2 \\
\text { and designated national network }>0\end{array}$ \\
\hline Rule 4 & $\begin{array}{l}\text { if route signing prefix }=3 \\
\text { and type of service under bridge }=5 \\
\text { and number of approach spans }<=2 \\
\text { and structure length }<=4,862 \\
\text { and minmum lateral underclearnace }<=28.3 \\
\text { and highway system of inventory route }<=0 \\
\text { and designated national network }<=0\end{array}$ \\
\hline Rule 5 & $\begin{array}{l}\text { if number of approach spans }<=2 \\
\text { and inven. Rte total horz clearance }<=11.8 \\
\text { and min vert. underclearance }<=2.32 \\
\text { and direction of traffic }<=1 \\
\text { and average daily truck traffic }>6 \\
\text { and designated national network }>0\end{array}$ \\
\hline Rule 6 & $\begin{array}{l}\text { if route signing prefix }=3 \\
\text { and type of service under bridge }=9 \\
\text { and designated national network }<=0\end{array}$ \\
\hline Rule 7 & $\begin{array}{l}\text { if number of approach spans }<=2 \\
\text { and min vert. underclearance }<=2.32 \\
\text { and waterway adequacy }=8 \\
\text { and highway system of inventory route }>0 \\
\text { and designated national network }<=0\end{array}$ \\
\hline Rule 8 & $\begin{array}{l}\text { if route signing prefix }=2 \\
\text { and type of service under bridge }=9\end{array}$ \\
\hline Rule 9 & $\begin{array}{l}\text { if route signing prefix }=4 \\
\text { and approach roadway width }>11.6 \\
\text { and num. of spans in main unit }<=6 \\
\text { and min vert. underclearance }<=2.32 \\
\text { and deck geometry }>4 \\
\text { and direction of traffic }<=1\end{array}$ \\
\hline Rule 10 & $\begin{array}{l}\text { if type of service on bridge }=5 \\
\text { and number of approach spans }<=2 \\
\text { and min vert. underclearance }<=2.32 \\
\text { and designated national network }>0\end{array}$ \\
\hline Rule 11 & $\begin{array}{l}\text { if approach roadway width }<=10.8 \\
\text { and type of service on bridge }=1 \\
\text { and number of approach spans }<=2 \\
\text { and inven. Rte total horz clearance }>11.8 \\
\text { and min vert. underclearance }<=2.32 \\
\text { and direction of traffic }<=1 \\
\text { and average daily truck traffic }<=15\end{array}$ \\
\hline Rule 12 & $\begin{array}{l}\text { if route signing prefix }=4 \\
\text { and year built }>1,984 \\
\text { and min vert. underclearance }<=2.32 \\
\text { and direction of traffic }<=1\end{array}$ \\
\hline Rule 13 & $\begin{array}{l}\text { if year built }>1,991 \\
\text { and approach roadway width }<=11.6 \\
\text { and bridge roadway width curb to curb }>11.5 \\
\text { and min vert. underclearance }<=2.32 \\
\text { and designated national network }<=0\end{array}$ \\
\hline Rule 14 & $\begin{array}{l}\text { if approach roadway width }>19.2 \\
\text { and number of approach spans }<=2 \\
\text { and min vert. underclearance }<=2.32 \\
\text { and designated national network }<=0\end{array}$ \\
\hline Rule 15 & $\begin{array}{l}\text { if number of approach spans }<=2 \\
\text { and min vert. underclearance }<=2.32 \\
\text { and direction of traffic }>1 \\
\text { and designated national network }>0\end{array}$ \\
\hline Rule 16 & $\begin{array}{l}\text { if route signing prefix }=5 \\
\text { and functional class of inventory rate }<=12 \\
\text { and length of max span }>17.7 \\
\text { and min vert. underclearance }<=2.32\end{array}$ \\
\hline
\end{tabular}


Table 9. Rule sets of Cluster 4.

\begin{tabular}{|c|l|}
\hline Cluster 4 & \multicolumn{1}{c|}{ Rule Description } \\
\hline Rule 1 & $\begin{array}{l}\text { if inventory route minimum vertical clearance }<=6.8 \\
\text { and number of approach spans }>6\end{array}$ \\
\hline Rule 2 & $\begin{array}{l}\text { if length of max span }>24.2 \\
\text { and waterway adequacy }=7 \\
\text { and highway system of inventory route }>0 \\
\text { and designated national network }<=0\end{array}$ \\
\hline Rule 3 & $\begin{array}{l}\text { if number of approach spans }>2 \\
\text { and minimum vertical underclearance }<=2.32\end{array}$ \\
\hline Rule 4 & $\begin{array}{l}\text { if route signing prefix }=3 \\
\text { and structure length }>486.2\end{array}$ \\
\hline Rule 5 & $\begin{array}{l}\text { if route signing prefix }=2 \\
\text { and type of service under bridge }=3\end{array}$ \\
\hline
\end{tabular}

Table 10. Rule sets of Cluster 5.

\begin{tabular}{|c|c|}
\hline Cluster 5 & Rule Description \\
\hline Rule 1 & minimum vertical underclearance $<=2.32$ \\
\hline
\end{tabular}

come from on-bridge usage. The deterioration rate is a little faster than that in Cluster 1, around 0.036/year.

There are 16 rules in Cluster 3, the most among all clusters. The rules are listed in Table 8 . It can be generalized that most bridges are bridges over rivers with waterway adequacy, or smaller ones not serving as the main roads and with lower load of traffic. As a result, the deterioration rate of the deck equals with that in Cluster 2, about $0.037 /$ year.

There are 5 rules in Cluster 4, as shown in Table 9. Rule 1 describes the bridge interchanges with other structure, and inventory route minimum vertical clearance $<=6.8 \mathrm{~m}$. Besides, number of approach spans $>6$, which is inferred that the bridge is an important part in the road network. But, the minimum underclearance is not high enough, leading to possibility of the deck's getting impacted by vehicles. Rule 2 refers to the length of max span $>24.2 \mathrm{~m}$, and waterway adequacy $=7$, indicating the slight chance of overtopping bridge deck and roadway approaching. Also, highway system of inventory route is more than 0 , signifying the inventory route is on the National Highway System (NHS). Nonetheless, designating national network is less than 0 , and showing that the bridge is not one for trucks to go through as regulated by the country. Therefore, it is generalized that the span length is long. Moreover, the bridge is a bridge over river without waterway adequacy under the bridge, so it is possible for water emerging over the bridge. Since it is an important road as well, in spite of no trucks passing, it will be influenced by the load of traffic and water split from the river. Rule 3 describes the number of approach spans is more than 2 , and the minimum vertical underclearance is equal or less than $2.32 \mathrm{~m}$. In other words, it is a bridge over river. Same to Rule 2, the deck is impacted by the load of traffic and water split from the river. Rule 4 points out that the route signing prefix is 3, signifying that the road of the bridge is state-leveled. The structure's length is more than $486.2 \mathrm{~m}$, which means it is not only a crucial road, but also a long bridge. In Rule 5, the route signing prefix $=2$ ant it is a U.S. numbered highway. Secondly, the type of service under bridge is 3 , indicating the usage is for Pedestrian-bicycle. Therefore, it is an important road of bridge with considerable traffic load.

Overall, it is deducted that the bridges in Cluster 4 are important. Besides, the traffic load is high, and the waterway is with in-adequacy due to bridge's being cross the river. Furthermore, water has been split over the deck for a long time, leading to faster deterioration rate of the deck, which is consistent to $0.043 /$ year in linear regression.

There is only one rule in Cluster 5; that is, minimum vertical underclearance is equal or less than 2.32 , referring to the bridge over river. It has also been split by water in the waterway under the bridge, causing the fastest deck deterioration rate, $0.047 /$ year or so.

\section{CONCLUSIONS}

This research proposes to categorize the bridges into several clusters with the same deterioration tendencies by means of data mining, clustering, and classification. Then, it tries to find out the factors and rules that have effects on clustering, and regulates clear rules of bridge clustering. NBI basic database and historical database are then utilized to processed case analysis, and one of the main structures, deck, is processed with linear regression. The findings show the analysis models of this study are worthy of consulting, and can serve as reference for value-added analysis of bridge's database in the future. Selecting Florida state with similar environments to Taiwan for analysis, this research finds that traffic flow and status of waterway has great influences. However, the bridges in Taiwan have been threatened by extreme climate. For example, debris flow or flood has severe impact on substructure of bridge. When succeeding researches in the future undertaking analysis with database of bridges in Taiwan, relative attributes of environment must be recorded, or data mining with insufficient and inappropriate attribute analysis will result in negative effects on the analytical results. Consequently, this study suggests that in addition to discovering knowledge with additional methods of data mining in the future, we have to note whether the current attributes are sufficient enough. Also, the standards of filling in the attributes in database must be set up to avoid the errors from human cognitions. By this way, we can therefore bring the database set up painstakingly to a full play, feedback to the bridge maintenance sections to carry out preventive maintenance, and ensure the good status of bridges and safety of the users.

\section{ACKNOWLEDGMENTS}

This research was supported by National Science Council (NSC 100-2218-E-008-007-). 


\section{REFERENCES}

1. AASHTO, Guidelines for Bridge Management Systems, American Association of State Highway and Transportation Officials, Washington, D.C. (1993).

2. Agrawal, A. K. and Kaaguchi, A., "Bridge element deterioration rates," Transportation Infrastructure Research Consortium, New York State Department of Transportation (2009).

3. Bolukbasi, M., Mohammadi, J., and Arditi, D., "Esimating the future condition of highway bridge components using National Bridge Inventory Data," Practice Periodical on Structural Design and Construction, Vol. 9, No.1, pp. 16-25 (2004).

4. Breiman, L., Friedman, J., Stone, C. J., and Olshen, R. A., Classification and Regression Trees, Chapman and Hall/CRC (1983).

5. DeLisle, R. R., Sullo, P., and Grivas, D. A., "Element-level bridge deterioration modeling using condition durations," Presented during 83rd TRB Annual Meeting, January 11-15, Washington, D.C. (2004).

6. Frank, E., Wang, Y., Inglis, S., Holmes, G., and Witten, I. H., "Using model trees for classification," Machine Learning, Vol. 32, pp. 63-76 (1998).

7. Kuo, R. J., Ho, L. M., and Hu, C. M., "Integration of self-organizing feature map and K-means algorithm for market segmentation," Computers and Operations Research, Vol. 29, pp. 1475-1493 (2002).

8. Lee, J., Sanmugarasa, K., Blumenstein, M., and Loo, Y. C., "Improving the reliability of a Bridge Management System (BMS) using an ANNbased Backward Prediction Model (BPM)," Automation in Construction,
Vol. 17, No. 6, pp. 758-772 (2008).

9. MacQueen, J. B., "Some methods for classification and analysis of multivariate observations," Proceedings of 5th Berkeley Symposium on Mathematical Statistics and Probability, University of California Press, Berkeley, pp. 281-297 (1967).

10. Mauch, D. C. and Madanat, S. M., "Semiparametric hazard rate models of reinforced concrete bridge deck deterioration," Journal of Infrastructure System, Vol. 7 No. 2, pp. 49-57 (2001).

11. Morcous, G., Rivard, H., and Hanna, A. M., "Modeling bridge deterioration using case-based reasoning," Journal of Infrastructure Systems, Vol. 8, No. 3, pp. 86-95 (2002).

12. Park, H. S. and Baik, D. K., "A study for control of client value using cluster analyzsis," Journal of Network and Computer Application, Vol. 29, pp. 262-276 (2006)

13. Phares, B. M., Rolander, D. D., Graybeal, B. A., and Washer, G. A., "Reliability of visual bridge inspection," Public Roads, Vol. 64, No. 5, pp. 22-29 (2001).

14. Quinlan, J. R., C4.5: Programs for Machine Learning, Morgan Kaufmann Publishers (1993).

15. U.S. DOT, Recording and Coding Guide for the Structure Inventory and Appraisal of the Nation's Bridges, U.S. Department of Transportation, Bridge Management Branch (1995).

16. Wang, Y. M. and Elhag, T. M. S. "Evidential reasoning approach for bridge condition assessment," Expert Systems with Applications, Vol. 34, No. 1, pp. 689-699 (2008). 